\title{
Comparative study of sinoatrial conduction time and sinus node recovery time ${ }^{1}$
}

\author{
Gerhard Steinbeck and Berndt Lüderitz \\ From the Medizinische Klinik I, Universität München (Klinikum Grosshadern)
}

\begin{abstract}
Atrial stimulation studies were performed in 5 normal patients (group $A$ ) and 4 patients with electrocardiographic evidence of sinoatrial disease (group $B$ ). The technique of premature atrial stimulation was used to calculate sinoatrial conduction time. Rapid atrial pacing was applied to measure maximum sinus node recovery time. In 4 cases both stimulation methods were repeated after intravenous administration of atropine Group $A$ had a sinoatrial conduction time of $56 \mathrm{~ms} \pm I I(S D)$ and a maximum sinus node recovery time of II22 ms \pm 158 . In 3 out of 4 patients with sinus node dysfunction a prolongation of sinoatrial conduction time could be demonstrated (145, 105, and $150 \mathrm{~ms})$. In addition, one showed probable sinus node exit block after premature atrial stimulation. Sinus node recovery time was excessively prolonged in 2 (3880 and $3215 \mathrm{~ms}$ ) and normal in the other 2 patients with sinoatrial disease (I 330 and $1275 \mathrm{~ms}$ ).

Atropine leads to a decrease of sinoatrial conduction time. Results indicate that sinus node recovery time may not be a reliable indicator of sinus node automaticity if sinoatrial conduction is disturbed. The premature atrial stimulation technique makes it possible to study the pattern of sinoatrial conduction and to evaluate its reaction to therapeutic drugs.
\end{abstract}

Analysis of atrial depolarization in the surface electrogram permits only an overall estimation of sinus node function. This involves the ability to act as an impulse generator and includes conduction of the impulse from the pacemaker site to the atrium (i.e. sinoatrial conduction).

Recently the method of rapid atrial stimulation was developed to measure sinus node recovery time which is thought to permit evaluation of sinus node automaticity (Rosen et al., I97I; Mandel et al., 1971). When sinus node recovery time was prolonged in patients with sinoatrial disease, this has been interpreted as a sign of a disturbed sinus node automaticity (Narula, Samet, and Javier, 1972; Mandel et al., 1972). However, results obtained by this method are variable and not always conclusive (Rios et al., 1972; Gupta et al., 1974).

Administration of atropine has been shown to result in a decrease of sinus node recovery time (Mandel et al., 1972). In other studies, however, an atropine-induced lengthening of sinus node recovery time was observed in single cases (Narula

Received 26 February 1975.

${ }^{1}$ Supported by Deutsche Forschungsgemeinschaft SFB 89 Kardiologie Göttingen. et al., 1972; Bashour, Hemb, and Wickramesekaran, 1973).

In 1973, Strauss et al., described a way of determining sinoatrial conduction time in man by use of the premature atrial stimulation technique. Thus, a differentiation between sinus node generator characteristics and sinoatrial conduction seems to be possible. In a previous publication a modification of this procedure for calculation of sinoatrial conduction time was described (Steinbeck, Körber, and Lüderitz, 1974). In the present study we report simultaneous determinations of sinoatrial conduction time and sinus node recovery time in 9 patients. Four of them were restudied after administration of atropine.

Our Results revealed a conspicuous prolongation of sinoatrial conduction time in 3 patients with sinoatrial disease. A disturbance of retrograde sinoatrial conduction during rapid atrial stimulation as well as a disturbance of antegrade sinoatrial conduction after cessation of atrial pacing may affect the apparent recovery interval of the sinus node. This reduces the significance of sinus node recovery time as an indicator of sinus node automaticity. Thus, for furthering our understanding of the underlying pathophysiological mechanisms in sinoatrial disease, 
both sinoatrial conduction time and sinus node recovery time should be measured.

\section{Patients and methods}

Nine patients were studied (see Table I).

Group A (Cases I-5) showed no signs of sinus node dysfunction. It included, however, one patient showing reflex slowing of sinus rate during massage of the carotid sinus (Case 2) and another with frequent premature ventricular extrasystoles (Case 5). Group B (Cases 6-9) had electrocardiographic evidence of sinoatrial disease with episodes of sinus rates less than $50 /$ min. In addition to sinus bradycardia, supraventricular tachycardia (Cases 6 and 9), spontaneous second degree sinoatrial block (Case 7), and junctional escape rhythm after a period of atrial arrest (Case 8) were observed in these patients.

All patients gave informed, written consent for evaluation of sinus node function. They were studied in the non-sedated state and did not receive any cardioactive drugs unless stated otherwise. In all patients sinus rhythm was present during the study.

A quadripolar electrode catheter was inserted via the basilic vein and the tip placed at the lateral wall of the right atrium. The distal pair of electrodes was used for stimulation. From the proximal pair of electrodes a high right atrial electrogram was simultaneously recorded with a standard electrocardiogram. For rapid atrial stimulation and premature atrial stimulation the Tektronix Pulse Generator System Series 2600 was used. Rectangular stimuli of twice diastolic threshold and $2 \mathrm{~ms}$ in duration were passed through an isolation transformer (Tektronix Type 2620). For calculation of sinoatrial conduction time, single premature stimuli were delivered with a variable time delay after the last spontaneous atrial depolarization. The bipolar atrial electrogram was used as trigger signal, and the entire atrial cycle was scanned.

\section{Definitions and measurements}

Applying the premature atrial stimulation technique, the following time intervals were measured.

I) The interval between the last two spontaneous atrial depolarizations preceding the stimulation impulse $\left(a_{1}-a_{2}\right)$.

2) The interval between the last atrial depolarization and the stimulus-induced atrial excitation (so-called curtailed cycle $a_{2}-a_{3}$ ).

3) The interval between the stimulus-induced atrial excitation and the next spontaneous atrial depolarization (so-called postextrasystolic cycle $a_{3}-a_{4}$ ).

Premature beats elicited late in the spontaneous atrial cycle are followed by a fully compensatory pause (no pacemaker reset: $a_{2}-a_{3}$ plus $a_{3}-a_{4}$ is twice the $a_{1}-a_{2}$ interval). Earlier premature beats are followed by a noncompensatory pause (pacemaker reset: $a_{2}-a_{3}$ plus $a_{3}-a_{4}$ is shorter than twice the $a_{1}-a_{2}$ interval (see Wenckebach, 1903; Eccles and Hoff, 1934; Bonke, Bouman, and van Rijn, 1969; Strauss et al., 1973)).

For calculation of sinoatrial conduction time we determined the postextrasystolic interval $\left(a_{3}-a_{4}\right)$ which was exactly at the borderline between fully compensatory and non-compensatory (Steinbeck et al., 1974). The $a_{2}-a_{3}$ interval at this borderline represents the shortest premature beat interval whose retrograde excitation front does not reach the sinus node, whereas earlier premature beats reset the pacemaker and may depress it (Bonke et al., 1969; Klein, Singer, and Hoffman, 1973).

Therefore, the postextrasystolic interval $a_{3}-a_{4}$ at this borderline, minus the spontaneous atrial cycle $a_{1}-a_{2}$, is equivalent to the sum of conduction time from atrium to the sinus node plus from sinus node to atrium. Half of the total sum of conduction time gives the sinoatrial conduction time.

The sinus node recovery time is defined as the time interval between the last paced atrial activation and the first spontaneous beat of sinus origin after cessation of rapid atrial stimulation. Sinus node recovery time was measured after stimulation with frequencies above sinus rate. The pacing rate was then increased by increments of Io or 20 beats $/ \mathrm{min}$. Each pacing period lasted one minute. The maximum sinus node recovery time is the longest time interval seen at any of the stimulation rates.

\section{Results}

The results of atrial stimulation studies are listed in Table I.

\section{Sinoatrial conduction time}

Group A patients had sinoatrial conduction times of $56 \mathrm{~ms} \pm$ II (mean $\pm \mathrm{SD}$ ), which are considered normal (Steinbeck et al., 1974). Of 4 group B patients, 3 had a conspicuous prolongation of sinoatrial conduction time.

The results of premature atrial stimulation in Case 6 are shown in Fig. I. When single beats are elicited after an interval equal to between 70 and IOO per cent of the preceding atrial cycle $a_{1}-a_{2}$, the sum of the $a_{2}-a_{3}$ and $a_{3}-a_{4}$ interval is about twice the $a_{1}-a_{2}$ cycle. Thus, these data agree with the theoretical line indicating fully compensatory pauses. If the curtailed cycles are shortened further, they are followed by non-compensatory pauses, as indicated by the data below the theoretical line of the compensatory pause. From this a sinoatrial conduction time of $145 \mathrm{~ms}$ is calculated.

Beats introduced early in atrial diastole are followed by abruptly shortened postextrasystolic intervals. The postextrasystolic atrial depolarization starts at the moment where it would have been expected if the premature beat had not occurred. The sum of the curtailed cycle $a_{2}-a_{3}$ and postextrasystolic cyle $a_{3}-a_{4}$ is equal to the preceding $a_{1}-a_{2}$ interval indicated by the data close to the theoretical broken line (Fig. I). This type of response is highly suggestive of sinus node entrance block of the premature beat.

In Case 7 a sinoatrial conduction time of $105 \mathrm{~ms}$ 
TABLE I Results of atrial stimulation studies in 9 patients

\begin{tabular}{|c|c|c|c|c|c|}
\hline Case no. & $\begin{array}{l}\text { Age (yr) } \\
\text { and sex }\end{array}$ & Arrhythmias & $\begin{array}{l}\text { Sinus rate } \\
\text { (per min) }\end{array}$ & $\begin{array}{l}\text { Sinoatrial } \\
\text { conduction time } \\
\text { (ms) }\end{array}$ & $\begin{array}{l}\text { Maximum sinus node } \\
\text { recovery time } \\
\text { (ms) }\end{array}$ \\
\hline
\end{tabular}

\begin{tabular}{|c|c|c|c|c|c|c|}
\hline \multicolumn{7}{|l|}{ Group $A$} \\
\hline I & 27 & $\mathbf{F}$ & - & 96 & 60 & 1050 \\
\hline 2 & 50 & $\mathbf{M}$ & Carotid sinus hypersensitivity & 96 & 40 & 895 \\
\hline 3 & 51 & $\mathbf{M}$ & 一 & 65 & 50 & 1205 \\
\hline 4 & 33 & $\mathbf{F}$ & 二 & 64 & 60 & 1310 \\
\hline 5 & 66 & $\mathbf{F}$ & Premature ventricular extrasystoles & 85 & 70 & 1150 \\
\hline \multicolumn{7}{|l|}{ Group $B$} \\
\hline 6 & 57 & $\mathbf{M}$ & $\begin{array}{l}\text { Sinus bradycardia, supraventricular } \\
\text { tachycardia }\end{array}$ & 62 & I45 & 1330 \\
\hline 7 & 61 & $\mathbf{F}$ & Sinus bradycardia, sinoatrial block & 57 & $\begin{array}{l}\text { Sinoatrial } \\
\text { exit block }\end{array}$ & 3880 \\
\hline 8 & 69 & $\mathbf{F}$ & $\begin{array}{l}\text { Sinus bradycardia, junctional escape } \\
\text { rhythm }\end{array}$ & 60 & 150 & 3215 \\
\hline 9 & 50 & $\mathbf{F}$ & $\begin{array}{l}\text { Sinus bradycardia, premature ventricular } \\
\text { extrasystoles, supraventricular } \\
\text { tachycardia }\end{array}$ & 69 & * & 1275 \\
\hline
\end{tabular}

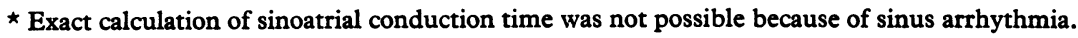

was determined (Fig. 2). Moreover, some impulses are followed by postextrasystolic intervals exceeding the other intervals by one basic cycle length. The escape beat was always of sinus origin and the following atrial cycle lengths were in the range of prepacing values. This indicates that an intermittent sinoatrial exit block after single premature beats is present as well as a prolongation of sinoatrial conduction time.

Case 8 had the longest sinoatrial conduction time ( $150 \mathrm{~ms}$ ) seen in any patients.

In Case 9 a considerable sinus arrhythmia did not allow an exact determination of the borderline between compensatory and non-compensatory pauses or, therefore, calculation of sinoatrial conduction time.

\section{Sinus node recovery time}

Values of maximum sinus node recovery time in group A are normal (Table I) (Narula et al., 1972). From Case 4, Io successive atrial cycle lengths after discontinuation of rapid atrial pacing at a frequency of 70, 90, IIO7 and I5O per minute are plotted in Fig. 3A. The interval from the last paced beat to the first beat of sinus origin is always the longest interval. Thereafter the cycle lengths gradually return to normal prepacing values, with some slightly decreased intervals (after pacing at 90 and $\mathrm{Iro} / \mathrm{min})$. All other patients of group A showed a similar pattern of successive atrial cycle lengths after rapid atrial stimulation.

Two patients of group B showed a normal maximum sinus node recovery time (Cases 6 and 9); the other 2 patients had a conspicuous prolongation of maximum sinus node recovery time (Cases 7 and 8) (see Table 1 ).

From Case 8, 10 successive atrial cycle lengths after cessation of rapid atrial stimulation are plotted in Fig. 3B. The first 3 atrial cycles after pacing at $90 / \mathrm{min}$ are prolonged by one basic cycle length. The next 3 intervals are abruptly shortened, being identical to normal prepacing atrial cycles. The seventh a-a interval is also twice the basic cycle length, the following cycles being only slightly longer than normal. From this it can be concluded that the first three and the seventh beat-to-beat interval after cessation of atrial pacing at $90 / \mathrm{min}$ are determined by a sinoatrial exit block with $2:$ I atrial response, in addition to depression of the sinus node pacemaker. Sinoatrial exit block with $3:$ I atrial response is superimposed on the value of 'sinus node recovery time' after cessation of pacing at $110 / \mathrm{min}$. An intermittent sinoatrial exit block is present after cessation of atrial pacing at $140 / \mathrm{min}$, not during the first beats but in the fourth and fifth atrial cycles. This is indicated by a sudden doubling of the atrial cycle length. 


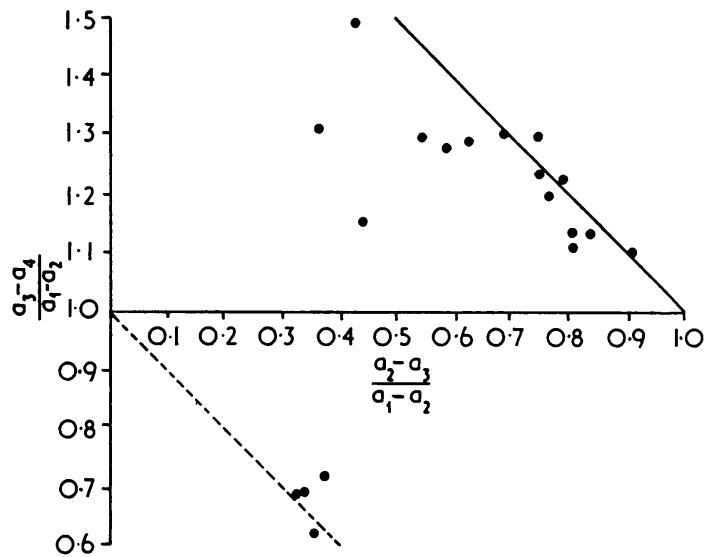

FIG. I Postextrasystolic cycle $a_{3}-a_{4}$ as a function of the curtailed cycle $a_{2}-a_{3}$ (Case 6). Both values are related to the preceding $a_{1}-a_{2}$ interval: $a_{1}-a_{2}$ interval $=963 \mathrm{~ms} \pm 54 \quad(n=19)$. Transition from compensatory to non-compensatory $a_{3}-a_{4}$ interval occurs at a curtailed cycle of about 70 per cent of the $a_{1}-a_{2}$ interval. Postextrasystolic interval $a_{3}-a_{4}$ at this borderline $(=130 \%)$, minus the spontaneous atrial cycle $a_{1}-a_{2}(=100 \%)$, represents conduction time into and out of the sinus node: sinoatrial conduction time $=145 \mathrm{~ms}$. Early premature beats are followed by abruptly shortened postextrasystolic intervals. This is highly suggestive of sinus node entrance block of the impulse, because $a_{3}$ demonstrated no increase in latency, the configuration of the postextrasystolic depolarizations was unchanged, and the subsequent sinus rate was not altered (Goldreyer and Damato, I97I).

Similarly abrupt changes of atrial cycle length were observed in Case 7 after cessation of rapid atrial stimulation as in the patient above. In this patient also a sinoatrial exit block was assumed to be present after premature atrial stimulation. These abrupt changes did not occur in Cases 6 and 9 or in any of the group A patients.

Atropine Two patients from each group were restudied 5 minutes after intravenous administration of I $\mathrm{mg}$ atropine (Table 2).

Sinoatrial conduction time was decreased in Cases I, 3, and 6 (Fig. 4). The transition from compensatory to non-compensatory postextrasystolic pauses takes place at an $a_{2}-a_{3}$ interval of 85 per cent of the $a_{1}-a_{2}$ cycle. From this a sinoatrial conduction time of $55 \mathrm{~ms}$ is calculated. Further shortening of the curtailed cycle within the range of non-compensatory pause results in a continuous

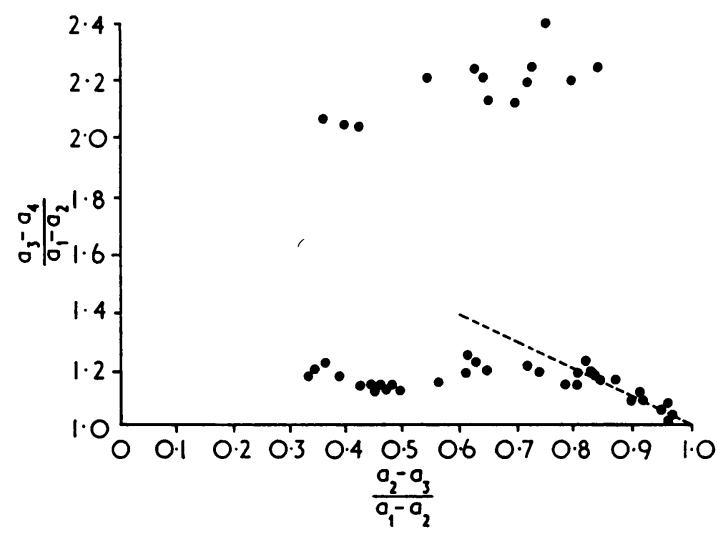

FIG. 2 Co-ordinates as in Fig. I (Case 7). $a_{1}-a_{2}$ interval $=1050 \mathrm{~ms} \pm 50(n=46)$. The borderline between compensatory and non-compensatory intervals $a_{3}-a_{4}$ is at about 80 per cent of $a_{1}-a_{2}$ : sinoatrial conduction time $=105 \mathrm{~ms}$. Single premature beats are followed by prolonged postextrasystolic intervals. For further explanation see text.

prolongation of the postextrasystolic cycle. A sinus node entrance block was not observed after early premature beats. In Case 9 sinus rhythm was regular after atropine, and a sinoatrial conduction time of $45 \mathrm{~ms}$ could be determined.

Atropine diminished maximum sinus node recovery time in both patients in each group (Table 2). 'Corrected maximum sinus node recovery time' (i.e. the maximum 'sinus node recovery time' in excess of the preceding sinus cycle length) was reduced by $325 \mathrm{~ms}$ in Case I, and by $238 \mathrm{~ms}$ in Case 9; it diminished only slightly in Case 3 (by $19 \mathrm{~ms}$ ), and in Case 6 (by $23 \mathrm{~ms}$ ).

The values of sinus node recovery time from Case 3 are shown after various stimulation frequencies before and after atropine (Fig. 5A). A positive relation between sinus node recovery time and pacing rate is not apparent; maximum sinus node recovery time is achieved at $130 / \mathrm{min}$ before and after drug administration. Atropine decreased sinus node recovery time at any pacing rate at which it was tested. Similar results were obtained in Case I, except that atropine raised the pacing rate giving rise to maximum sinus node recovery time from 120 to $150 / \mathrm{min}$.

Fig. $5^{\mathrm{B}}$ gives the results of Case 6 (group B). Maximum sinus node recovery time is observed after atrial pacing at a frequency of $80 / \mathrm{min}$. Periods of more frequent stimulation up to $130 / \mathrm{min}$ are followed by a shorter sinus node recovery 
(A)

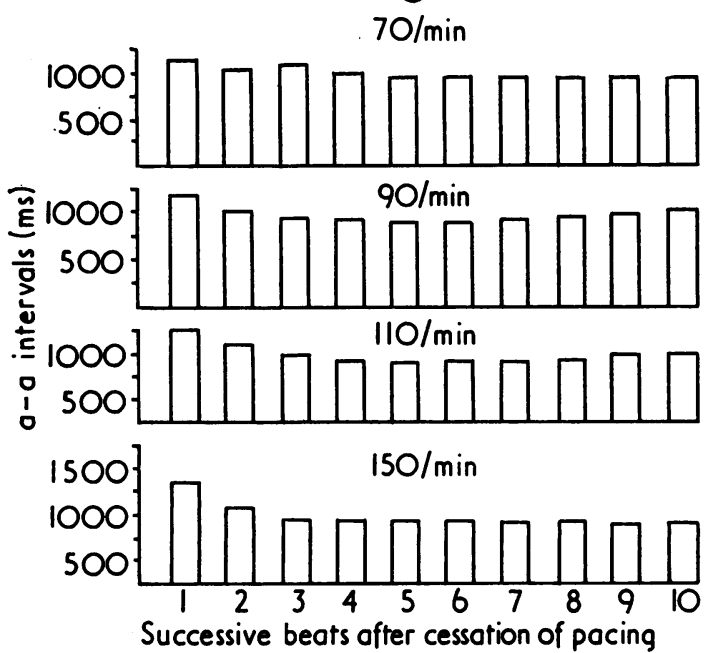

(B)

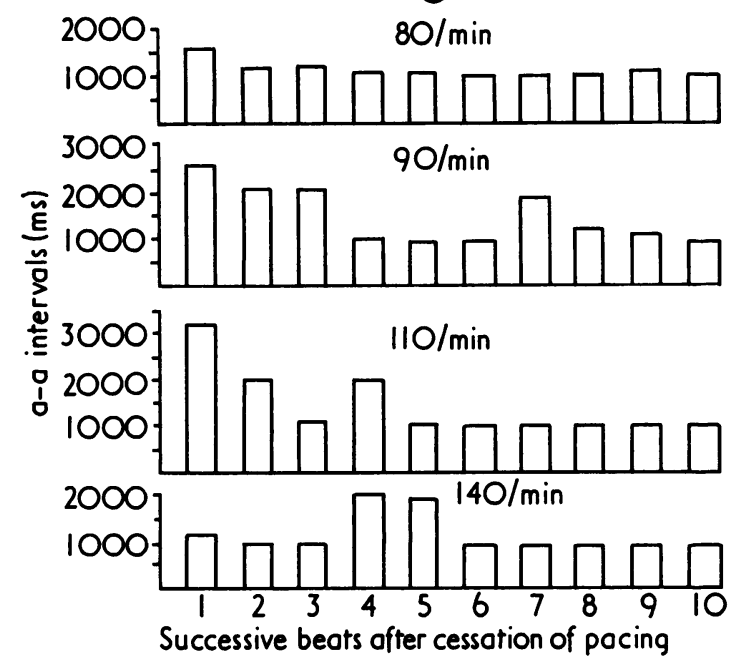

FIG. $3 A$ ) Ten successive atrial cycle lengths after rapid atrial pacing at 70, 90, I10, and 150/min (Case 4). Average sinus cycle before stimulation: $940 \mathrm{~ms}$ (see text). B) (Case 8). Stimulation rates: 80, 90, I10, and 140/min. Average sinus cycle before stimulation: $995 \mathrm{~ms}$. After the pacing periods of 90,110 , and I40/min considerable changes in atrial cycle lengths are observed, which differ exactly by one basic a-a interval. For further discussion, see text.

TABLE 2 Atrial stimulation after I mg intravenous atropine

\begin{tabular}{llll}
\hline Case no. & $\begin{array}{l}\text { Sinus rate } \\
\text { Imin }\end{array}$ & $\begin{array}{l}\text { Sinoatrial } \\
\text { conduction } \\
\text { time }(\text { ms })\end{array}$ & $\begin{array}{l}\text { Maximum sinus } \\
\text { node recovery time } \\
(\text { ms })\end{array}$ \\
\hline I & 120 & 25 & 600 \\
3 & 95 & 35 & 895 \\
6 & 83 & 55 & 1070 \\
9 & 83 & 45 & 900 \\
\hline
\end{tabular}

time. The pacing rate could not be raised above $\mathrm{r} 30 / \mathrm{min}$ because of the onset of angina pectoris. After administration of atropine the pacing rate causing maximum sinus node recovery time is increased to $120 / \mathrm{min}$. After stimulation at $130 / \mathrm{min}$, sinus node recovery time is longer after administration of atropine than before.

\section{Discussion}

It is the purpose of this study to demonstrate the advantage of simultaneous measurement of sino-

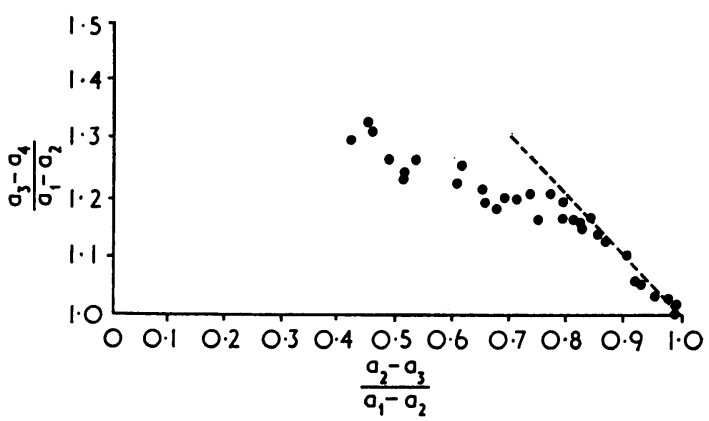

FIG. 4 Same patient as in Fig. I after admission of atropine I mg intravenously. Co-ordinates as in Fig. $I$. $a_{1}-a_{2}$ interval $=726 \mathrm{~ms} \pm 14(n=32)$. Atropine leads to a decrease of sinoatrial conduction time $(55 \mathrm{~ms})$.

atrial conduction time and sinus node recovery time for the detailed analysis of the pathophysiological conditions underlying sinoatrial disease.

In 1973, Strauss et al., applying the premature atrial stimulation technique, first reported a way of determining sinoatrial conduction time in man.

We used a modification of this procedure, which 

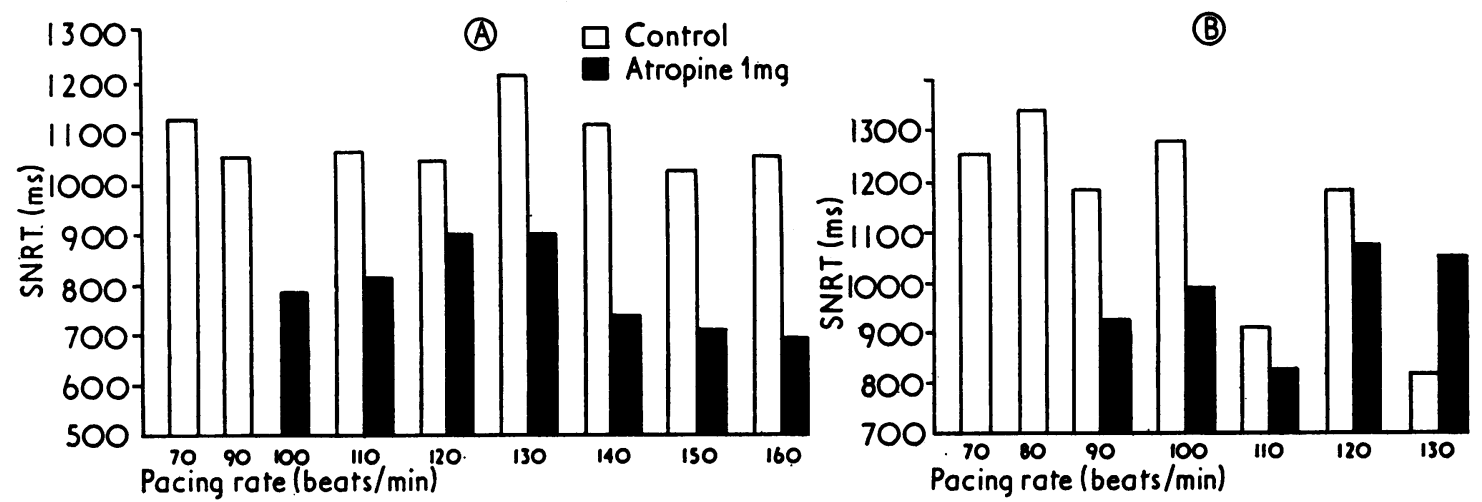

FIG. $5 A$ ) Sinus node recovery time (ms) after rapid atrial stimulation with various frequencies before and after atropine I mg intravenously (Case 3). Sinus rate is $65 / \mathrm{min}$, after atropine 95/min. After pacing had been stopped at 80 and $100 / \mathrm{min}$ (before atropine) a premature atrial extrasystole occurred first so that sinus node recovery time could not be measured. B) Coordinates as in Fig. $5 A$ (Case 6). Sinus rate is 62/min, after atropine 83/min. For further explanations see text.

avoids the possibility of sinus node depression after premature beats influencing calculation of sinoatrial conduction time (Steinbeck et al., 1974). On the other hand, this method of calculation may lead to an underestimate of the true sinoatrial conduction time (Miller and Strauss, 1974). Anterograde and retrograde sinoatrial conduction times may not be identical. Sinoatrial conduction time is, however, half of the sum of conduction time from the site of electrodes used for atrial bipolar electrogram into the sinus node and back from the sinus node to the recording electrodes. Nevertheless, the value of 56 $\mathrm{ms} \pm \mathrm{II}$ in 5 patients without evidence of sinoatrial disease agrees with experimental results derived from transmembrane action potential measurements in a spontaneously beating preparation of the isolated right atrium of the rabbit (West, 1955; Hoffman and Cranefield, 1960; Sano and Yamagishi, I965; Strauss and Bigger, 1972).

The method of rapid atrial stimulation has been applied to measure sinus node recovery time, which is thought to permit evaluation of sinus node automaticity (Rosen et al., 1971; Mandel et al., 197I). However, two conditions have to be fulfilled if observations made with overdrive suppression are to provide a valid measure of sinus node automaticity.

I) Successful retrograde sinoatrial conduction of the impulse delivered to the right atrium.

2) Successful antegrade sinoatrial conduction immediately after the period of atrial pacing (Strauss and Bigger, 1973).

Our study of 5 patients without any signs of abnormal sinus node function (group A) revealed a normal sinoatrial conduction time as well as a normal sinus node recovery time.

Different results were obtained in group B. Four patients with electrocardiographic evidence of sinoatrial disease were analysed. Two (Cases 7 and 8) showed an excessively prolonged sinus node recovery time. With the results of premature atrial stimulation in these patients in mind, we think it unlikely that prolongation of sinus node recovery time was brought about by severe sinus node depression alone. Both patients showed a very prolonged sinoatrial conduction time. In addition, one of them showed intermittent sinoatrial exit block after single premature beats as a sign of a more severe impairment of sinoatrial conduction. After cessation of rapid atrial pacing, abrupt changes of atrial cycle length from one beat to another were observed, in both patients, differing by one basic interval. This pattern of abruptly changing successive atrial cycle lengths after the period of atrial pacing was never seen in the 5 patients with normal sinoatrial conduction time. We, therefore, suppose that impairment of antegrade sinoatrial conduction, after cessation of rapid atrial stimulation, resulting in sinoatrial exit block of various degrees, was superimposed on sinus node depression in the 2 patients with apparently very prolonged sinus node recovery times (Cases 7 and 8 ).

Case 6 with evidence of sinoatrial disease demonstrated a prolonged sinoatrial conduction time in the presence of a normal maximum sinus node recovery time. Atropine, I mg intravenously, reduced sino- 
atrial conduction time as well as maximum sinus node recovery time. After atropine, however, the pacing rate causing maximum sinus node recovery time was raised from 80 to $120 / \mathrm{min}$. At a stimulation frequency of $130 / \mathrm{min}$, the recovery time was longer after atropine than before (see Fig. $5 \mathrm{~B}$ ).

On the basis of the premature atrial stimulation studies (Fig. I and 4) we interpret the results of rapid atrial stimulation in this patient as follows: Sinoatrial conduction is grossly impaired. At low frequencies a maximum of impulses is conducted from the atrium to the sinus node and causes maximum sinus node recovery time. At higher stimulation rates it is assumed that impairment of sinoatrial conduction increases; as a consequence, fewer impulses penetrate to discharge the sinus node pacemaker thus leading to an apparently paradoxical shortening of sinus node recovery time. This explains the normal value of maximum sinus node recovery time which would probably be prolonged in the presence of an adequate retrograde sinoatrial conduction. Atropine is thought to improve retrograde sinoatrial conduction. As a result, maximum sinus node recovery time is observed after a considerably increased pacing frequency, and sinus node recovery time at $130 / \mathrm{min}$ is longer after atropine than before.

Our results indicate that sinus node recovery time may not be a reliable indicator of sinus node automaticity if sinoatrial conduction is disturbed. It seems that sinus node entrance block during rapid atrial stimulation leads to a shortening, and sinus node exit block after rapid atrial pacing, to a prolongation of the sinus node recovery time. These mechanisms offer an explanation for the observation that patients with sinoatrial disease may sometimes show greatly prolonged or normal sinus node recovery times besides moderate prolongation of sinus node recovery time after rapid atrial stimulation. Results may also be obscured by the occurrence of sinus nodal re-entry beats after atrial pacing (Narulo, 1975).

The premature atrial stimulation technique provides a means of studying the pattern of sinoatrial conduction and evaluating its reaction to drugs.

\section{References}

Bashour, T., Hemb, R., and Wickramesekaran, R. (1973). An unusual effect of atropine on overdrive suppression. Circulation, 48, $91 \mathrm{I}$.
Bonke, F. I. M., Bouman, L. N., and van Rijn, H. E. (1969). Change of cardiac rhythm in the rabbit after an atrial premature beat. Circulation Research, 24, 533 .

Eccles, J. C., and Hoff, H. E. (1934). The rhythm of the heart beat. II - Disturbances of rhythm produced by late premature beats. Proceedings of the Royal Society, London, Series $B, 115,327$.

Goldreyer, B. N., and Damato, A. N. (197I). Sinoatrialnode entrance block. Circulation, 44, 789.

Gupta, P. K., Lichstein, E., Chadda, K. D., and Badui, E. (1974). Appraisal of sinus nodal recovery time in patients with sick sinus syndrome. American fournal of Cardiology, $34,265$.

Hoffman, B. F., and Cranefield, P. F. (1960). Electrophysiology of the Heart. McGraw-Hill, New York.

Klein, H. O., Singer, D. H., and Hoffman, B. F. (1973). Effects of atrial premature systoles on sinus rhythm in the rabbit. Circulation Research, 32, 480.

Mandel, W. J., Hayakawa, H., Allen, H. N., Danzig, R., and Kermaier, A. I. (1972). Assessment of sinus node function in patients with the sick sinus syndrome. Circulation, 46, $76 \mathrm{r}$.

Mandel, W. J., Hayakawa, H., Danzig, R., and Marcus, H. S. (197I). Evaluation of sino-atrial node function in man by overdrive suppression. Circulation, 44, 59.

Miller, H. C., and Strauss, H. C. (1974). Measurement of sinoatrial conduction time by premature atrial stimulation in the rabbit. Circulation Research, 35, 935.

Narula, O. S. (1975). Sinus node re-entry. Circulation, 50, III4.

Narula, O. S., Samet, P., and Javier, R. P. (1972). Significance of the sinus-node recovery time. Circulation, $45,140$.

Rios, J. C., Bashour, T., Cheng, T. O., and Motomiya, T. (1972). Atrial pacing in sick sinus node syndrome (abstract). Circulation, 45 and 46, Suppl. II, 21 I.

Rosen, K. M., Loeb, H. S., Sinno, M. Z., Rahimtoola, S. H., and Gunnar, R. M. (197I). Cardiac conduction in patients with symptomatic sinus node disease. Circulation, $43,836$.

Sano, T., and Yamagishi, S. (1965). Spread of excitation from the sinus node. Circulation Research, 16, 423.

Steinbeck, G., Körber, H.-J., and Lüderitz, B. (1974). Die Bestimmung der sinuatrialen Leitungszeit beim Menschen durch gekoppelte atriale Einzelstimulation. Klinische Wochenschrift, 52, $115 \mathrm{I}$.

Strauss, H. C., and Bigger, J. T., Jr. (1972). Electrophysiological properties of the rabbit sinoatrial perinodal fibers. Circulation Research, 3I, 490.

Strauss, H. C., and Bigger, J. T., Jr. (1973). The authors reply. An unusual effect of atropine on overdrive suppression. Circulation, 48, $91 \mathrm{I}$.

Strauss, H. C., Saroff, A. L., Bigger, J. T., Jr., and Giardina, E. G. V. (1973). Premature atrial stimulation as a key to the understanding of sinoatrial conduction in man. Circulation, 47, 86.

Wenckebach, K. F. (1903). Ueber die Dauer der compensatorischen Pause nach Reizung der Vorkammer Säugethierherzens. Archiv für Physiologie (Leipzig), p. 57.

West, T. C. (1955). Ultramicroelectrode recording from the cardiac pacemaker. Fournal of Pharmacology and Experimental Therapeutics, $115,283$.

Requests for reprints to Dr. G. Steinbeck, Medizinische Klinik I (Klinikum Grosshadern), D 8000 München 70, Marchioninistr. 15, W. Germany. 